\title{
Assessment of students' learning when working in groups
}

\author{
Karin Forslund Frykedal and Eva Hammar Chiriac
}

\section{Linköping University Post Print}

N.B.: When citing this work, cite the original article.

This is an electronic version of an article published in:

Karin Forslund Frykedal and Eva Hammar Chiriac, Assessment of students' learning when working in groups, 2011, Educational research (Windsor. Print), (53), 3, 331-345.

Educational research (Windsor. Print) is available online at informaworld ${ }^{\mathrm{TM}}$ :

http://dx.doi.org/10.1080/00131881.2011.598661

Copyright: Taylor \& Francis (Routledge)

http://www.routledge.com/

Postprint available at: Linköping University Electronic Press

http://urn.kb.se/resolve?urn=urn:nbn:se:liu:diva-69997 
'final version 2011-06-08'

\title{
Assessment of students' learning when working in groups
}

\author{
Karin Forslund Frykedal ${ }^{1}$ and Eva Hammar Chiriac \\ Department of Behavioural Sciences and Learning, University of Linkoping, Linkoping, Sweden
}

\begin{abstract}
The overarching interest in this project is to gain knowledge about what happens in the meeting between group work and assessment in pedagogical practice. Grounded theory methodology, was used as methodology and data have been gathered by focus group interviews with 11 teachers teaching students aged 11 to 16 years. The results show that teachers primarily used informal approaches, a general language and the descriptions about what they assessed and how assessment was carried out. This article elucidates some of the teachers' problems concerning assessment in group work and some pedagogical implications based on empirical findings.
\end{abstract}

Background: The overarching interest in this project is to gain knowledge about what happens in the meeting between group work and assessment in pedagogical practice. There seems to be a tension between the demand for individual assessment of students' knowledge and abilities and the demand to teach students collaboration abilities through group work. A previous study concerning teachers' management of group work as a classroom activity (Hammar Chiriac \& Forslund Frykedal, 2011) reveals that assessment is a highly relevant factor. In addition, teachers seem to experience difficulties and acknowledge some challenges and problems as regards assessing students working in a group.

Purpose: The main purpose of this study was to obtain not only increased knowledge of how teachers assess individual learning occurring in group work, but also explore how teachers manage the emerging challenges. An additional purpose was, with support from previous research within the area, to provide a means of handling these challenges.

\footnotetext{
${ }^{1}$ Corresponding author. Email: karin.forslund.frykedal@liu.se
} 
'final version 2011-06-08'

Sample: Data were gathered by means of three focus group interviews. The informants were 11 teachers. They taught students aged 11 to 16 years in compulsory education in Sweden during the spring of 2009.

Design and method: Grounded theory methodology, together with the theoretical perspective of symbolic interactionism, was used to increase comprehension of the teachers' problems when assessing learning outcome in group work. The transcribed discussions in the focus groups were analysed by means of theoretical sampling, and a number of categories emerged.

Results: The results show that teachers primarily used informal approaches when they assessed students' knowledge and abilities in group work situations. The teachers used a general level when talking about assessment and the descriptions about what they assess were vague. In the teachers' accounts of what is assessed it is possible to distinguish both the product and the process carried out at an individual as well as at a group level. Furthermore, the results reveal two different assessment strategies, that is how the assessment was carried out; by teachers (from outside the group) or by students (from inside the group). Additionally, the results disclosed that the teachers have difficulties in concretising and verbalising what and how they assess. The teachers also experienced uncertainty and contradictory demands concerning assessment of students in group work. They were concerned about this difficulty.

Conclusion: The teachers were of the opinion that group work is used foremost to develop group work abilities and not as a means of acquiring academic knowledge. This influenced the teachers' mode of using assessment, that is, they focussed on assessing the collaborative abilities. This article elucidates some of the teachers' problems concerning assessment in group work and some pedagogical implications based on empirical findings. Research-based theories and models within these areas could increase teachers' confidence, which, in turn, could increase good practice, their ability to use group work as a mode and also their competence in assessment.

Keywords: assessment; group work; pedagogical practice; teachers' presumption; classroom; collaboration 
'final version 2011-06-08'

\section{Introduction}

Group work is a teaching strategy that promotes academic achievement and socialisation (Baines, Blatchford and Chowne, 2007; Gillies, 2003a, 2003b; Johnson and Johnson, 2004; Summers, Beretvas, Svinicki and Gorin, 2005). By interacting with others, students learn to inquire, share ideas, clarify differences, and construct new understandings. In this way, the students learn to use language to explain issues which, in turn, help them to construct new ways of thinking (Webb and Mastergeorge, 2003). Nevertheless, this picture contrasts with other contemporary research which has revealed that collective time in the classroom is decreasing in favour of individual time (Baines, Blatchford and Kutnick, 2003; Ekholm, 1996; Galton, Hargreaves, Comber, Wall and Pell, 1999; Granström, 2006) and a number of teachers still seem reluctant to use group work as a pedagogical tool in the classroom. This is contrary to the trend in the rest of society where collaboration is the most common approach (Granström, 2006; Stymne, 1992).

One stated reason for the decreasing collective time in the classroom is that group work may give rise to classroom activities and processes among students, which might be difficult for the teacher to control (Granström, 2006; Kohn, 1992; Williams and Sheridan, 2010). A second possible reason may be that teachers lack knowledge of how to manage group work and how to organise it in a profitable way (Lotan, 2006, 2008). In a recently completed study, teachers clearly demonstrated that they primarily expect the students to develop the ability to collaborate, and not principally to acquire subject knowledge, during group work. In addition, teachers expressed the concern that the students would have difficulties in 'managing the curriculum' and 'achieving lifelong learning' if group work were to be used as a pedagogical tool (Hammar Chiriac and Forslund Frykedal, 2011). Moreover, students' previous negative experiences of group work in the classroom may also be a conceivable explanation. Finally, assessing students' achievements during group work may be difficult and quite a challenge for the teachers (Gillies and Boyle, 2010; Hammar Chiriac and Forslund Frykedal, 2011; Postholm, 2008; Webb 1997). Assessment is, generally, a complex phenomenon and encountered within a group activity it may becomes even more complicated and difficult to manage.

Most curricula prescribe that teachers assess students' individual knowledge. Between supplying students with occasions to work collaboratively, giving the students opportunities to attain their grades and also evaluate their knowledge, there is an embedded dilemma. The dilemma emerges as the knowledge is to be assessed and marked individually in a collaborative 
'final version 2011-06-08'

situation. In the present study, we focus on this identified dilemma, with the intention of acquiring greater understanding relating to assessment when using group work. To our knowledge, this is a rather neglected research area and little attention has been paid to research about the assessment of individual learning that occurs in a group.

\section{Aim of the study}

The main purpose of this investigation is to obtain increased knowledge not only about how teachers assess individual learning that occurs in group work, but also how teachers manage challenges emerging in relation to the assessment. An additional aim is, with support from previous research within the area of assessment, to provide a means of handling these challenges.

\section{Previous research}

Previous research concerning assessment of individual learning in group work shows that teachers perceive difficulties in assessing students' knowledge and proficiency in group work (Gillies and Boyle, 2010; Hammar Chiriac and Forslund Frykedal, 2011; Postholm, 2008; Webb 1997). Teachers (Ross and Rolheiser, 2003) and students (Forslund Frykedal, 2008; Hammar Chiriac and Granström, 2009, 2011) are uncertain not only about what should be assessed and how it can be carried out, but also whether the assessments are directed towards the individual or the group. Ross and Rolheiser (2003) also point out the importance of transparent assessments, which means that students have to know what will be assessed and also how it will be carried out.

In a study by Gillies and Boyle (2010) teachers reported that they conducted more informal than formal assessments. This was, above all, achieved by walking around and observing who was active in the task and who was proceeding correctly in the groups. The teachers in this study also assessed the groups' presentations of their work and implemented an individual assessment after the completed group work. Johnson and Johnson (2004) suggested that a collectively produced assignment should not be assessed individually since it creates competition among students, contrary to group assessment, which creates interdependence among the group members.

Assessment of group work could be undertaken with help from the students through self and peer assessment (see for example, Brew, Riley and Walta, 2009; Bushell, 2006; Sharp, 2006; 
'final version 2011-06-08'

Zhang, Johnston and Bagci Kilic, 2008). Ethical problems may arise when students use self and peer assessments. To evaluate one's peers' performance and have one's own performance assessed by others could be potentially interpreted as insulting, which could create strain (Brew et al., 2009). However, according to Brew et al. (2009), the students become more self-confident, independent and reflective when using self and peer assessment.

Assessment is often discussed by the use of concepts such as summative and formative assessment. In summative assessment the purpose is to establish the student's knowledge and proficiency compared to certain objectives, whereas in formative assessment the purpose is to establish a student's knowledge and proficiency to give feedback for further development. Additionally, the aim with formative assessment is to give responses to individuals during the working process (Black, Harrison, Lee, Marshall and William, 2003; Brew, et al., 2009) in order to let the proficiencies and abilities come to light and to elucidate aspects which have to be developed. Thus, there are two different learning outcomes that could be assessed; academic achievement or collaborative and learning strategies.

Assessment and learning are interdependent and difficult to separate (Johnson and Johnson, 2004). Using assessment is, therefore, an effective tool in focusing on the students' own learning processes (Black and William, 1998a, 1998b). The students might, thereby, be active in their own assessment process to control their own learning (Cohen, 1994, 1997). Research demonstrates that formative assessment is considerably more supportive than summative assessment. Graduate assessments, which are typically summative assessments, have, furthermore, a tendency to create competition rather than knowledge development (Black and William, 1998a, 1998b; Black et al., 2003; William, Lee, Harrison and Black, 2004). Studies by Lotan (2008) suggest that increased permeability and formative assessment during group work create more advanced work. When assessment and feedback are connected to students' learning there are considerable possibilities for more qualitative group work (Ladyschewsky, 2006). Research about professionalism (Colnerud and Granström, 2002) asserts that a common professional language is fundamental in order for teachers to be able to communicate and develop their pedagogical practice and their competence concerning assessment. 
'final version 2011-06-08'

\section{Methodological and theoretical approach}

The empirical study follows the methodology of symbolic interactionism (Blumer, 1969; Charon, 2006; Mead, 1967). The use of symbolic interactionism enables an exposure of the social processes in which the teacher is a part, and which also exerts an influence on their presumption, communication and actions when assessing knowledge and abilities in group work situations. From a symbolic interactionistic point of view, the surrounding world is perceived to be social interpretations of meaning through a definition of the situation (Blumer, 1969; Charon, 2006; Mead, 1967). This presupposes a view of reality as containing a multiplicity of realities and a view of social life as a process. Teachers' communication and actions are ruled by their interpretation of the situation. However, they do not react immediately to the objective reality but instead to their interpretations of other persons' actions and what they, in interaction with their own thoughts, define in the situation, which is influenced by means of previous occurrences as well as thoughts about the future. This implies that when teachers talk in a focus group about how they use assessment in group work, they are influenced by: earlier experiences, their future intentions around assessment as well as, how they defined the focus-group situation.

\section{Data collection}

The empirical material was collected through three focus groups (Millward, 2007; Morgan, 1997). The focus groups offered an opportunity to study how teachers in a group setting collectively discuss questions concerning assessment in collaborative situations. The purpose was to develop an understanding of how the teachers, together, construct a meaning of assessment of group work and how they discuss pros and cons. The focus group interviews were carried out without any difficulties. Both researchers acted as moderators but in separate focus groups. Besides keeping the dialogue on track, the moderator also had to ensure that all questions were discussed. All teachers were actively involved in the discussion.

The informants came from three schools in different counties in the south of Sweden. Schools from different social and geographical areas were included and one focus group of teachers from each school participated in the study. Teachers who were teaching students aged 11-16 years in compulsory education were represented in the study. The teachers in a focus group could be from the same working team or just from the same school. In all, the research group consisted of 11 informants, 10 female and one male. Each focus-group interview lasted; for 
'final version 2011-06-08'

an average of 78 minutes, which corresponds to a total data corpus of nearly four hours. See Table 1 below.

[Table 1 near here]

\section{Analysis}

The present study is inspired by the comparative method grounded theory (Charmaz, 2006; Glaser, 1978; Glaser and Strauss, 1967; Strauss and Corbin, 1998) as a methodological approach. Grounded theory studies the social reality from the actors' perspective by analysing communications and actions in real situations. The purpose of grounded theory is to conceptualise social processes by creating empirically based categories through substantive coding, and provide clear connections among them through theoretical coding, so forming a unit - that is, a theoretical model. In this study, we used substantive coding and theoretical coding and constructed a theoretical model. The use of grounded theory was beneficial since we wanted to capture the social process around teachers' use of assessment within group work. This is an approach which, together with the theoretical perspective, could increase comprehension about teachers' problems when assessing learning outcomes in group work.

The discussions in the focus groups were audio-taped and transcribed, and the analysis began with an open coding very close to the empirical material. During the first coding, several codes emerged. These, in turn, were elaborated and allocated into new parts in order to create wider sets of codes and become more abstract, so as to gradually form categories. Early in the process two categories were constructed, namely what is assessed and how is the assessment performed. The analysis continued, focusing on the two categories, and new codes related to them were constructed from the empirical data. With the comparative method, another four categories emerged. Two were related to what is assessed, namely the product or the process within the group work. The other two were related to how the assessment is performed, from the students' perspective, that is, inside the group, or the teachers' perspective, that is, outside the group.

To make the categories satisfactorily filled and refined, theoretical sampling was used. This was done by recoding the empirical data using the six categories mentioned above. The procedure also controlled when further selection from the data was necessary. Based on the analyses and the 
'final version 2011-06-08'

coding, through the whole process, notes surfaced. To find out how the relations among the categories were related to each other, theoretical coding was used. Thereby, patterns and connections between the categories emerged, for example at the group and individual levels. The categories and their relationships formed the basis for understanding the processes that appeared in the meeting between group work and assessment of knowledge and ability in the collaborative work. Finally, the results were drafted with support from the categories and the notes.

\section{Ethical issues}

The four ethical principles of the British Psychology Society (BPS) based on, (a) respect, (b) competence, (c) responsibility, and, (d) integrity, have been practised throughout the study (BPS, 2004). In line with ethical principles, concern for the participants' interests has been emphasised (APA (American Psychological Association), 2002; Barett, 2007; BPS, 2004). The quality in this qualitative research has been assured and measured based on validity and reliability (Bryman, 2001).

\section{Results}

The twofold purpose of group work, that is, to develop the ability to collaborate and to acquire academic knowledge, seemed to be a challenge for the teachers. The issue became even more challenging when the groups were working in different locations in the school and the teachers' chances of observing the groups for more than short periods were limited. This problem emerged in the teachers' statements, but at the same time they had difficulties in describing exactly what was problematic.

To frame the text we begin with a description of (a) the teachers' opinions about group work and what should be assessed in group work. Then follows a section about (b) what is actually assessed, and (c) how assessment is accomplished.

\section{The teachers' opinions about what should be assessed}

Previous studies have shown that teachers use group work with the purpose of getting students to attain collaboration abilities and not first and foremost for academic learning or subject knowledge (Hammar Chiriac and Forslund Frykedal, 2011). 
'final version 2011-06-08'

The assumption that teachers use group work as a strategy to develop the students' group work abilities and not as a means for the students to acquire academic knowledge certainly influences the mode of assessment. According to the teachers, the general purpose of assessing group work was, (a) to control the students' activity and accountability, (b) to measure social competence and level of attainment towards course objectives, and (c) to form a basis for grading. With this general point of departure from our earlier study kept in mind, the results of the analysis regarding the assessment of group work will now be presented.

\section{What is assessed}

The teachers' descriptions about what is assessed are vague. The descriptions are mostly on a general level and there is a lack of a common vocabulary in concretising what exactly is measured. In the teachers' accounts of which aspects, that is, what, were assessed in group work, it is possible to distinguish both product and process. The product is the result of the students' work, while process is mainly considered as the collaboration between the students when they work on a common task. Both aspects were important and must, according to the informants, form an integral part of the assessment of group work. However, it seemed to be easier for the teachers to talk about the product more than the process. But in terms of the extent of the discussions, the teachers spent considerably more time talking about the assessment of the process. In other words, academic learning or subject knowledge was not in focus. Besides the division into process and product, there was also a classification based on the group and individual levels.

\section{Products that are assessed}

When it came to assessing the group's results or outcome, the teachers estimated the value of aspects, such as (a) content, (b) final product, and (c) report. Each of the aspects might be assessed both at a group level and an individual level, and the teachers seemed to use both of these possibilities in parallel.

According to the interviewed teachers, Content is not only about reproduction of facts-(eg in a written text or in an oral presentation), but also about the students' critical thinking and criticism of the sources. The use of library sources was valued more highly than, for instance, the 
'final version 2011-06-08'

use of the Internet. The results suggest that teachers only seem to assess content at the group level.

The final product was a significant basis for assessment at both the group and the individual levels. How the final product turns out depends on the task, and, consequently, a text, a movie or a construction will be assessed according to different criteria. The teachers assessed the final product as a whole (group level), as well as assessing if and how group members assumed responsibility (individual level) during the work process. Furthermore, the teachers often highlighted the importance of contribution and participation to the joint final product as an individual standard.

Finally, teachers also assessed the students' reports regarding the group task at both levels. Reports may be carried out in several ways and consequently the assessments differed in accordance with the report. At a group level, the teachers assessed aspects such as content, performance and teaching aspect. If the report included learning opportunities for the audience, the teachers regarded this in a positive light.

I must say that I look a great deal on the presentation too. I think it is very important that they are able to present their .... what they have been working on during so many weeks, in a way that others may learn something from the presentation.

When it comes to oral presentations, the teachers also assessed language, mode of presentation and contact with the audience. On the individual level, teachers just seemed to scrutinise each group member's contribution.

The findings therefore indicated that assessment concerning the final product and the report was performed at both the group and individual levels, while content - the one aspect concerning academic knowledge - was only assessed at the group level.

\section{Processes that are assessed}

The process was defined, by the teachers, as 'the way to acquire knowledge' and consisted of the aspects (a) collaboration, (b) activity, and (c) communication.

Collaboration comprised, on the one hand, the students' joint work, (which the teachers called 'the whole lot') and, on the other hand, the identification of 'who has done what' to facilitate individual appraisal. In the assessment, two aspects were considered - firstly, whether 
'final version 2011-06-08'

the students were capable of collaborating (group level), and, secondly, whether everybody 'does one's share' and 'does one's very best' (individual level).

Activity and keeping to the task were, according to the teachers, utterly important in collaborative activities. It was equally vital to look at how the group actually works and whether the students 'keep to the subject' (group level). The will to assume responsibility and to push the work forward through urging and 'really getting mates going' (individual level) were also considered to be significant and highly valued.

Communication in the group was another significant aspect valued at both levels. To be able to discuss and argue were competences assessed at group level, while proficiency to speak, listen, give and take instructions were appraised on an individual level. Another important aspect was each individual student's ability to 'open up in a group', 'dare to express oneself', and 'dare to present in front of a large group'.

To sum up the results concerning what is assessed, it is evident that the teachers followed the assumption that group work is used as a strategy to develop group work abilities and not as a means to acquire academic knowledge. This influenced the teachers' mode of using assessment, that is, they focused foremost on collaborative abilities and not on academic knowledge. The teachers used a general level of address when talking about assessment and the descriptions about what they assessed were vague. For a summary see Figure 1.

\section{How assessment is carried out}

The teachers reported that the assessment of learning that occurred in group work was made in different ways, but they were not always specific in their descriptions of how the assessments were carried out.

I usually sneak around a little, and listen when they [the students] are working. They are quite used to that by now. I also chat a little in general with them. Then I check and see and then I ask them questions, when they had a discussion, okay, has everybody come to terms now... and some students say yes, and then they are quiet for a while, and then it comes, 'no not really'. 
'final version 2011-06-08'

The assessment could be carried out by teachers from outside or carried out by students from inside the group.

\section{Assessments carried out by teachers}

Besides the 'sneaking around' and observing, the outside assessment was accomplished by using a matrix where the students' proficiency could be registered (group level). Tests were unusual in connection with collaborative situations, but one or two tests (individual level) every term were compulsory. These supplemented the assessment of theoretical knowledge, whereas presentations at the end of group work were always assessed. In the presentations, the teachers also focused on observable proficiencies. It was important to give positive and constructive feedback and not offend a student in public.

I: But if you think somebody has done a poor presentation, how do you handle that?

T: Hm...but I usually say that...I think it's good if you practise this one more time. I think you should do a little bit better here [...] thus, I don't think I understand what you mean! It could depend on me...but I'd be grateful if you can find out more about it.

In summary, the teachers assessed the product as well as the process at both the group and individual levels but the descriptions about them were rather vague.

\section{Assessment carried out by students}

When the teachers involved the students in assessing their own knowledge or that of their peers, they used self and peer assessment. This evaluation inside the group is a complement to the evaluation from outside made by the teacher. Self assessment could, according to the teachers, be used to assess metacognitive skills about collaboration and attitudes in the group. This means that the students, (a) assess their own work in the group, (b) assess their own role in the group, and (c) make suggestions for improvement (that is, at both the individual and group levels). Self assessment was used occasionally after the presentations through discussions in the classroom as well as in individual reports, but there were no concrete descriptions from the teachers about how these assessments were carried out. 
'final version 2011-06-08'

Using logbooks was another strategy to accomplish assessment from inside the group. It was Logbooks were used for both self and peer assessment. The purpose of the logbooks was to continuously write down and reflect on the group processes in order to have a basis for the assessment of, (a) the students' own activity levels and contributions, (b) the peers' activity levels and contributions, and (c) the group's joint contributions. Occasionally, the content of the logbooks could be discussed in the group, with respect to the pros and cons of the group work.

Peer assessment had been tried in different ways at both the group and individual levels, as well as in different subjects, with varying experiences. One example was taken from language education and a collaboration task in which all the members helped each other through the assignment. The intention was that the group should work with a common text, it should be selfcontrolled, and the students should take responsibility for each other's knowledge acquisition. In this case the group was not allowed to present the results until all the individuals in the group had acquired the knowledge demanded.

So, it's some sort of control you know... the group is, should be self-controlled you know $[\ldots]$. All in the group should be sure that everyone has all the knowledge and not until then were they allowed to have their presentation.

This was one mode of self assessment that was hard to manage. In this situation, the teacher's experience was that she put too much pressure on the students, for which they were not quite ready.

I felt that it was, it was a little (laugh) too much pressure on them. I felt that they weren't ready for that. Because some students get so strained, and... scared.

The teachers talked a lot of the importance of protecting the students' integrity, and this could be a problem in relation to self assessment. They thought that the students generally were not mature enough to take responsibility for assessments and it was too hard for some students. One solution was to train the students to calibrate their assessments against specific criteria.

One way to combine the outside and inside perspectives was to give feedback from both teachers and students intertwined with the presentations. Sometimes, individual written 
'final version 2011-06-08'

evaluations were also carried out, in which students gave more exhaustive answers and where they also 'dared to tell things they otherwise wouldn't'.

To sum up the results with reference to what is assessed, a general inference is that assessment was carried out by the teachers (from outside the group) and by students (inside the group) at both levels. Furthermore, the teachers mainly used informal strategies when they assessed students' knowledge and abilities in group activities. A summary of what was assessed, how the assessment was carried out, and by whom, can be found in Figure. 1.

[Figure 1 near here]

\section{Conclusions}

The results reveal that teachers thought generally that group work was used, first and foremost, to develop group work abilities and not as a means to acquire academic knowledge. This influenced the teachers' mode of using assessment, that is, they focussed on assessing the collaborative abilities and not on academic knowledge. The teachers used a general level of discourse when talking about assessment and the descriptions of what they assessed were vague.

Furthermore, the teachers in this study primarily used informal approaches when they assessed students' knowledge and abilities in group work situations, and the results indicate that there was a great deal of uncertainty among teachers and ambiguity as to both what is to be assessed and how it can been done. In Figure 1, the results are summarised with respect to the teachers' reports of what they assessed concerning products and processes and the assessment strategies that were used. It is only in the first (products at group level) and last boxes (assessment strategy at individual level) that there are reports concerning the assessment of academic knowledge. The aspects being assessed in all other boxes relate to collaboration abilities.

Additionally, the results demonstrate that assessment was carried out by the teachers themselves (from outside the group) and by the students (inside the group). The teachers' indistinct descriptions of how they assess abilities and knowledge could also be explained by the uncertainty about how to use group work so that the students gain subject knowledge. This was demonstrated by the difficulties that teachers had in talking about how assessment could be carried out. 


\section{Discussion}

The use of symbolic interactionism in the study (Blumer, 1969; Charon, 2006; Mead, 1967) enabled an exposure of the processes, in which the teachers were a part, and made visible their presumptions about the assessment of knowledge in group work situations. Theories and theoretical concepts from earlier research, together with the theoretical perspective, were useful in interpreting the problems teachers described in the focus-group interviews. This, in turn, makes it possible to make proposals for further development in pedagogical practice. Consequently this study has implications which could be useful in pedagogical practice.

\section{Mostly collaboration abilities which are assessed}

Group work, from a learning perspective, functions as both an object, that is, learning to collaborate in groups, and as a means, that is, a base for obtaining knowledge (Baines et al., 2007; Gillies, 2003a, 2003b; Johnson and Johnson, 2004; Summers et al., 2005). The teachers expressed the view that both aspects were important and that both parts were included in the assessment. However, assessment of collaboration was more prominent in the discussions than concrete descriptions of daily practice. This could be explained by the teachers' opinion that group work is mainly used for the purpose of getting students to develop collaboration abilities rather than subject knowledge (Hammar Chiriac and Forslund Frykedal, 2011). The results make clear that the students' activities were in focus and that they were informally assessed, as in Gillies and Boyle's (2010) study. Concerning what is assessed, it became evident in our study that mostly it was the group's collaborative abilities that were assessed.

Results from the present study also confirmed that assessments were constructed by two different approaches, from outside the group - to be carried out by teachers, and from inside the group - to be carried out by students through self and peer assessment. Practising self and peer assessment could, according to Brew et al. (2009), give the students more self-confidence and independence, as well as engendering a more reflective approach. However, the teachers were afraid of putting too much pressure on the students, and they also wanted to protect the students' integrity, which they thought could be problematic in self and peer assessment. Through this line of action the students did not appear to get any opportunity to take control of their own learning (Black and William, 1998a, 1998b). 
'final version 2011-06-08'

Teaching includes two phenomena, that is, learning and assessment, which are difficult to separate (Johnson and Johnson, 2004; Black and William, 1998a, 1998b). They are reciprocal, and if the students are given opportunities to influence their own learning, they must also have the opportunities to influence the assessment of it. Ross and Rolheiser (2003) confirm the importance of distinct objectives and criteria for assessment on behalf of both teachers and students. In this empirical study, teachers used informal assessment (Gillies and Boyle, 2010) and an indistinct vocabulary when discussing how to carry out assessment. Moreover, the teachers used few concepts and exposed an embryonic professional language in discussing assessment. Thereby, the students received little concrete information about what would be assessed and how it would be done. Teachers also experienced uncertainty and contradictory demands regarding assessment of students in group work. They were concerned about this difficulty and described it as being in a 'trap'.

In order to make formal curriculum-based assessments, it is important that teachers are trained to use group work as a means, that is, a base from which knowledge can be obtained. The importance of having access to a professional language, theories, models, and management competence cannot be neglected in this case (Colnerud and Granström, 2002; Granström, 2006). Knowledge of assessment and marking seems to be a weak area within the teaching profession (Gillies \& Boyle, 2010; Kuisma, 2007; Zang, et al., 2008). Previous research (se for instance Black \& Wiliam, 1998a, 1998b; Black, et al., 2003; Johnson \& Johnson, 2004) a number of concepts of importance to assessment but also tools that can be useful in assessment. Students and teachers can jointly clarify the what, when, and how of assessment, and on which level, (that is, individual or group), and together create useful tools for assessment (Johnson and Johnson, 2004). Certainly, such conduct will make the assessment more understandable for the students and also increase justice and confidence in assessment. Consequently, the students have to take more responsibility for assessments, and, thereby, they will be able to influence their own learning process (Black \& Williams, 1998a, 1998b).

With support from relevant previous research, (se for instance Black \& Wiliam, 1998a 1998b; Black, et al., 2003; Gillies \& Boyle, 2010; Ross \& Rolheiser, 2003; Webb, 1997; Brew, et al., 2009) we have been able to develop research findings about assessment of group work that could be useful for the teachers' daily work, and to reduce their insecurity around assessment. Previous research in combination with our research findings support the implications presented in 
'final version 2011-06-08'

Table 2. Teachers could, by using this research, obtain access to a set of concepts to use in conversations and to problematise the area of assessment in group work, for instance, formative and summative assessment along with assessment from inside or outside the group. The purpose of assessment (what is assessed) and methods (how the assessment is implemented) are other examples of useful concepts. Research-based theories and models within these areas could increase teachers' confidence, which in turn could improve their daily practice and their abilities to use group work as a mode, and, in addition, increase their competence concerning assessment (Cohen, 1994, 1997; Johnson and Johnson, 2004; Lotan, 2006, 2008).

[Table 2 near here]

\section{References}

Baines, E., Blatchford, P. and Chowne, A. (2007) Improving the effectiveness of collaborative group work in primary schools: Effects on science attainment. British Educational Research Journal, 33, 663-680.

Baines, E., Blatchford, P. and Kutnick, P. (2003) Changes in grouping practices in primary and secondary school. International Journal of Educational Research, 39, 9-34.

American Psychological Association (APA) (2002) The ethical principles of psychologists and code of conduct. Retrieved August 2, 2008 from http://www.apa.org/ethics/code2002.html

Barett, M. (2007) Practical and ethical issues in planning research, in G. Breakell, S. Hammond, C. Fife-Schaw and J.A Smith (eds), Research Methods in Psychology, (London: SAGE Publications), pp. 24-48.

Black, P., Harrison, C., Lee, C., Marshall, B. and William, D. (2003) Assessment for Learning: Putting it into Practice. (Buckingham: Open University Press).

Black, P. and William, D. (1998a) Assessment and classroom learning. Assessment in Learning, $5,7-74$.

Black, P. and William, D. (1998b) Inside the black box: Raising standards through classroom assessment. Phi Delta Kappan, 80 (2), 139, (9).

Blumer, H. (1969) Symbolic Interactionism: Perspective and Method. (Berkeley, CA: University of California Press). 
'final version 2011-06-08'

British Psychological Society (BPS) (2004) Code of conduct, ethical principles \& guidelines. Retrieved August 2, 2008 from http://www.bps.org.uk/document-download-area/documentdownload\$.cfm?file_uuid=6D0645CC-7E96-C67F-D75E2648E5580115\&ext=pdf

Brew, C., Riley, P. and Walta, C. (2009) Education students and their teachers: Comparing views on participative assessment practices. Assessment \& Evaluation in Higher Education, 34, $641-657$.

Bryman, A. (2001). Social research methods. (Oxford: University Press).

Bushell, G. (2006) Moderation of peer assessment in group projects. Assessment \& Evaluation in Higher Education, 31, 91-108.

Charmaz, K. (2006) Constructing Grounded Theory (London: SAGE Publications).

Charon, J. M. (2006) Symbolic Interactionism: An Introduction, anIinterpretation, an Integration (London: Prentice Hall).

Cohen, E. G. (1994) Restructuring the classroom: Conditions for productive small groups. Review of Educational Research, 64, 1-35.

Cohen, E. G. (1997) In the land of testing, in E. G. Cohen and R. Lotan (eds), Working for Equity in Heterogeneous Classrooms., (New York: Teachers College Press), pp. 167-203.

Colnerud, G. and Granström, K. (2002) Regard the teacher profession.(Stockholm: HLS).

Ekholm, M. (1996) School Climate and Educational Change: Stability and Change in Nine Swedish Schools, (EERA Bulletin, 2).

Forslund Frykedal, K. (2008). Students' course of action in group-work. About levels of ambition and patterns of behaviour in collaborative situations. (Doctoral thesis, Linköping University, Sweden).

Galton, M. J., Hargreaves, L., Comber, C., Wall, D. and Pell, A. (1999) Inside the Primary Classroom: 20 Years on, (London: Routledge).

Gillies, R. M. (2003a) The behaviours, interactions, and perceptions of junior high school students during small-group learning. Journal of Educational Psychology, 95, 137-147.

Gillies, R. M. (2003b) Structuring cooperative group work in classrooms. International Journal of Educational Research, 39, 35-49.

Gillies, R. M. and Boyle, M. (2010) Teachers' reflections on cooperative learning: Issues of implementation. Teaching and Teacher Education, 26, 933-940.

Glaser, B. G. (1978) Theoretical sensitivity, (Mill Valley: The Sociology Press). 
'final version 2011-06-08'

Glaser, B. G. and Strauss, A. (1967). The Discovery of Grounded Theory, (New York: Aldine de Gruyter).

Granström, K. (2006) Group phenomena and classroom management in Sweden. In C. M. Evertson and C. S. Weinstein (eds), Handbook of Classroom Management: Research, Practice, and Contemporary Issues, (Mahwah: Lawrence Erlbaum Associates, Publisher), pp. $1141-1160$.

Hammar Chiriac, E. and Forslund Frykedal, K. (Forthcoming 2011) Management of Group Work as Classroom Activity.

Hammar Chiriac, E. and Granström, K. (2009) Prerequisites for meaningful group work Students' experiences of co-operation, in S. Jern and J. Näslund (eds) Dynamics Within and Outside the Lab: Proceedings from the 6th Nordic Conference on Group and Social Psychology, Lund University, May, 2008. Linköping: Linköping University.

Hammar Chiriac, E. and Granström, K. (Forthcoming 2011) Teachers' leadership and students' experience of group work. Teachers and Teaching: Theory and Practice.

Johnson, D. W. and Johnson, R. T. (2004) Assessing Students in Groups: Promoting Group Responsibility and Individual Accountability, (Thousand Oaks: SAGE).

Kohn, A. (1992) Resistance to cooperative learning: Making sense of its deletion and dilution. Journal of Education, 174, 38-55.

Ladyschewsky, R. (2006) Aligning assessment, reward, behaviours and outcomes in group learning tasks. Enhancing student learning: 2006 Evaluations and assessment conference refereed papers. Retrieved November 2, 2010 from http://lsn.curtin.edu.au/eac2006/abstracts.html

Lotan, R.A. (2006) Managing groupwork in the heterogeneous classroom, in C. M. Evertson and C. S. Weinstein (eds), Handbook of Classroom Management: Research, Practice, and Contemporary Issues, (Mahwah: Lawrence Erlbaum Associates, Publisher), pp. 525-540.

Lotan, R.A. (2008) Developing language and mastering content in heterogeneous classrooms, in R. M. Gillies, A. Ashman and J. Terwel (eds) The Teacher's Role in Implementing Cooperative Learning in the Classroom, (Brisbane: Springer), pp. 187-203.

Mead, G. H. (1967) Mind, Self, and Society. From the Standpoint of a Social Behaviorist. [Edit by Charles W. Morris] (Chicago: The University of Chicago Press). 
'final version 2011-06-08'

Millward, L. J. (2007) Focus groups, in G. Breakell, S. Hammond, C. Fife-Schaw and J. A Smith (eds) Research Methods in Psychology, (London: SAGE Publications), pp. 274-292.

Morgan, D. L. (1997) Focus Groups as Qualitative Research, (London: SAGE Publications).

Postholm, M. B. (2008) Group work as a learning situation: A qualitative study in a university classroom. Teachers and Teaching: Theory and Practice, 2, 143-155.

Ross, J. A. and Rolheiser, C. (2003) Student assessment practice in co-operative learning, in R. M Gillies and A. F. Ashman. Co-operative Learning: The Social and Intellectual Outcomes of Learning in Groups, (London: RoutledgeFalmer), pp. 119-135.

Sharp, S. (2006) Deriving individual student marks from a tutor's assessment of group work. Assessment \& Evaluation in Higher Education, 31, 329-343.

Strauss, A. and Corbin, J. (1998) Basics of Qualitative Research, (London: SAGE publications).

Stymne, I. (1992) The Structure of Work: Analyzing Interaction in Small Task Groups,

(Stockholm: Stockholm University).

Summers, J. J., Beretvas, S. N., Svinicki, M. D. and Gorin, J. S. (2005) Evaluating collaborative learning and community. The Journal of Experimental Education, 73, 165-188.

Webb, N. (1997) Assessing students in small collaborative groups. Theory Into Practice, 36, 205-213.

Webb, N. and Mastergeorge, A. (2003) Promoting effective helping in peer-directed groups. International Journal of Educational Research, 39, 73-97.

William, D., Lee, C., Harrison, C. and Black, P. (2004) Teachers developing assessment for learning: Impact on student achievement. Assessment in Education: Principles, Policy \& Practice, 11:1, 49-65.

Williams, P. and Sheridan, S. (2010) Conditions for collaborative learning and constructive competition in school. Educational Research, 52, 335-350.

Zhang, B., Johnston, L. and Bagci Kilic, G. (2010) Assessing the reliability of self and peer rating in student group work. Assessment \& Evaluation in Higher Education, 33. 329-340. 


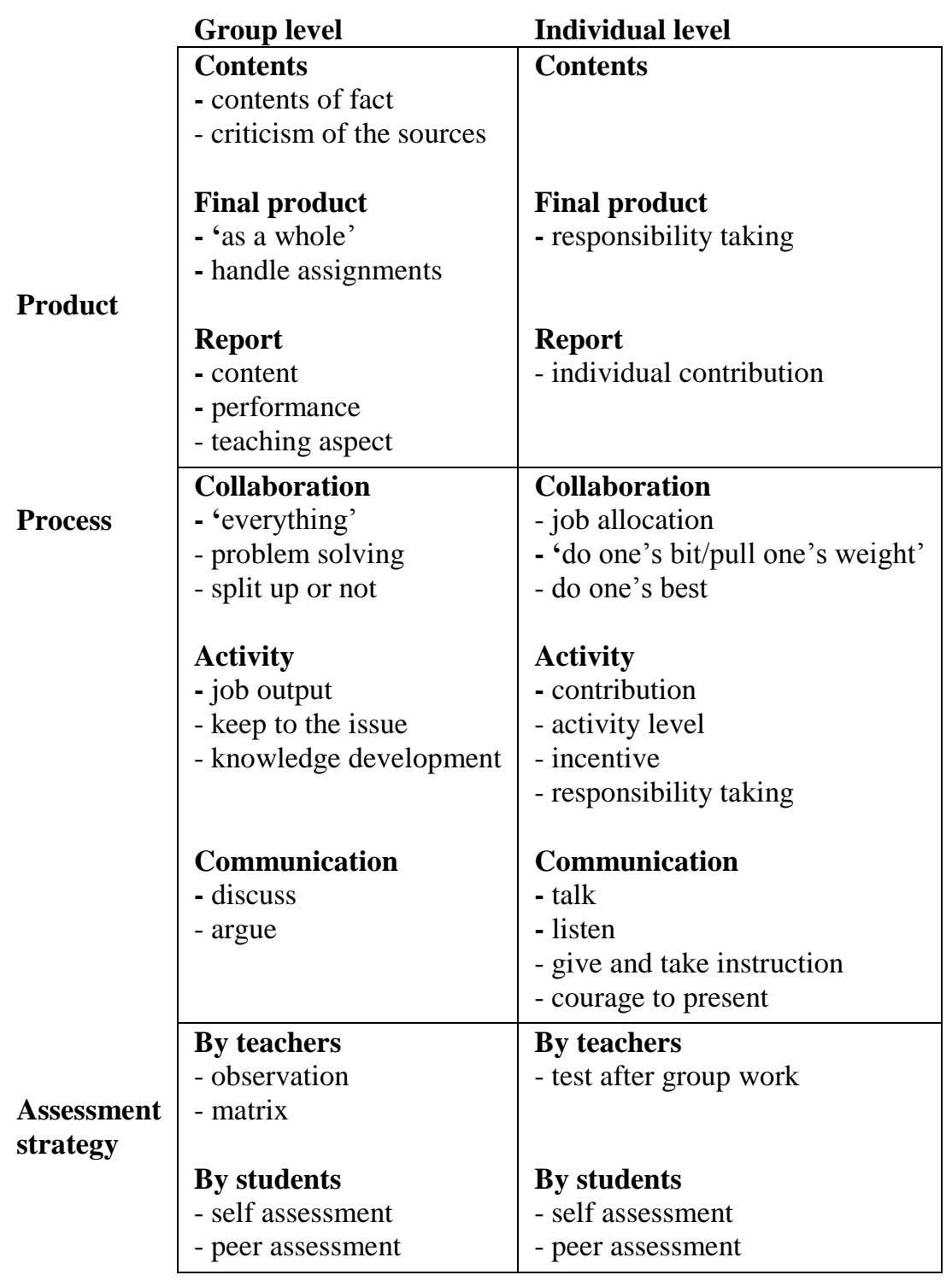

Figure 1. Aspects being assessed in group work. 
'final version 2011-06-08'

Table 1

Details of the focus groups

\begin{tabular}{llll}
\hline Focus group & School & Participants & Time (min) \\
\hline 1 & A-School & 3 & 97 \\
2 & B-School & 4 & 76 \\
3 & C-School & 4 & 60 \\
\hline
\end{tabular}

Table 2.

Proposed pedagogical implications based on the present findings and previous research

\begin{tabular}{llll}
\hline Teachers' problems & Research -based conclusions & Pedagogical implications \\
\hline & & & \\
The teachers mostly assess & $\begin{array}{l}\text { Understand that it feasible to Produce experiences that group work } \\
\text { collaboration abilities since they use } \\
\text { group work as an object to develop } \\
\text { group work abilities and not as a means assess both may lead to theoretical learning or } \\
\text { to learn subject knowledge. }\end{array}$ & $\begin{array}{l}\text { pertaining to product and students'subject knowledge. } \\
\text { process. }\end{array}$
\end{tabular}

Teachers have difficulties in sharing responsibility for the assessment with the students.

Teachers have problems verbalising and specifying purposes and strategies for individual assessment in group work situations.

The teachers experience uncertainty and contradictory demands regarding assessment in groups. This makes them feel trapped.
The students need to become more self-confident, independent and reflective when using self and peer assessment.

Teachers lack a professional language with useful terminology, concepts and models.

There is a need to point out and emphasise:

- clarity and permeability

- formative or summative

- product or process

- from outside or inside.
Teachers and students together create tools to use in assessment.

Practise appraisal to increase justice and confidence in assessment.

Theories for developing a professional language are available. Teachers need to discuss and problematise assessment.

Together, with students, teachers should elucidate the what, when and how of assessment and on which level, individual or group, it should be undertaken. 